\section{Tea consumption: A cause of constipation?}

Uncontrolled clinical observations in our outpatient clinic suggested that severe constipation in young adults was related to tea consumption of one to two litres daily. We have therefore carried out a study on healthy volunteers.

\section{Subjects, methods, and results}

Twelve healthy volunteers aged 23-30 years participated in the study, which comprised two test periods of seven days. Diet was unrestricted except for beverages, which in one test period were limited to two litres of tap water daily and in the other to two litres of tea (four bags of $2 \mathrm{~g}$ Assam/ Ceylon Brook Bond tea per litre, steeped for five minutes). On day 5 of each test period the subjects ingested 20 radio-opaque plastic markers, and daily excretions of urine and faeces were collected on days 5,6 , and 7 . On day 7 body weight was recorded and blood samples taken. Faeces were analysed for mass, total bile acid concentration, 1 and number of plastic markers excreted (to measure intestinal transit time ${ }^{2}$ ). Urine analysis included volume, specific gravity, and oxalate concentration. Each subject served as his own control, and the sequence of the test periods was randomised. The rank sum test was used for paired observations.

Significantly fewer plastic markers were excreted over 72 hours in the tea period than in the water period $(p<0.05)$, indicating significantly increased intestinal transit time (figure). The mean faecal bile acid output

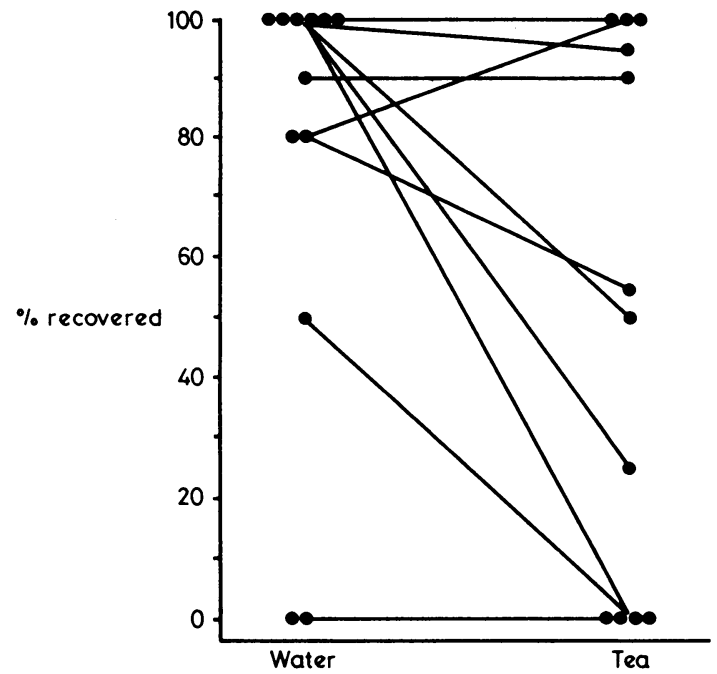

Intestinal transit times expressed as percentages of plastic markers recovered in 72 hours. Difference between water and tea periods: $\mathrm{p}<0.05$.

decreased from 436 to $310 \mu \mathrm{mol} / 24 \mathrm{~h}(\mathrm{p}<0.05)$ during the tea period, whereas faecal mass showed only a slight and non-significant reduction. Specific gravity of urine increased from 1014 to $1017 \mathrm{~g} / \mathrm{l}(\mathrm{p}<0.05)$ in the tea period, and urine oxalate excretion rose from 0.36 to $0.41 \mathrm{mmol}(3.2$ to $3.7 \mathrm{mg}) / 24 \mathrm{~h}(\mathrm{p}<0.10)$; the urine volume showed only a slight non-significant increase. During the tea period the following mean plasma concentration were increased $(p<0.05)$ : albumin from 599 to $623 \mu \mathrm{mol} / 1(4.13$ to 4.30 $\mathrm{g} / 100 \mathrm{ml}$ ); creatinine from 73 to $82 \mu \mathrm{mol} / 1$ ( 826 to $927 \mu \mathrm{g} / 100 \mathrm{ml}$ ); urate from 0.27 to $0.29 \mathrm{mmol} / 1(4.5$ to $4.8 \mathrm{mg} / 100 \mathrm{ml})$; sodium from 128 to $133 \mathrm{mmol}$ $(\mathrm{mEq}) / 1$; potassium from 3.5 to $3.8 \mathrm{mmol}(\mathrm{mEq}) / 1$; and calcium from 1.97 to $2.11 \mathrm{mmol} / 1(7.8$ to $8.4 \mathrm{mg} / 100 \mathrm{ml})$. No changes were seen in carbamide, haemoglobin, or phosphate values. There was no change in body weight.

\section{Comment}

The effect of tea was probably due to theophylline, which (presumably via the kidneys) causes extracellular dehydration, a secondary increase in intestinal fluid absorption, and hence constipation. This hypothesis agrees with the findings in a study of constipating cocoa products. $^{3}$ The estimated daily intake of theophylline with tea in our study was roughly $100 \mu \mathrm{mol},{ }^{4}$ sufficient to increase the renal glomerular filtration rate and decrease tubular reabsorption. ${ }^{5}$ The raised plasma concentrations of various components and the increased intestinal transit time during the tea period support the hypotheses of dehydration and constipation.

We suggest that the relation between fluid consumption and intestinal transit time should be considered in studies evaluating the influence of compounds-for example, dietary fibres and drugs-on intestinal function.

This study was supported by the Danish Medical Research Council, grant No 512-16144, and the Hässle Foundation. Mrs Kirsten Rasmussen gave expert technical help.

${ }^{1}$ Malchow-Møller A, Arffmann S, LaRusso NF, Krag E. Enzymatic determination of total $3 \alpha$-hydroxy bile acids in faeces. In: Abstracts of the XI international congress of gastroenterology. Hepato-gastroenterology. Stuttgart, New York: Georg Thieme Verlag, 1980:suppl:39.

${ }^{2}$ Hinton JM, Lennard-Jones JE, Yong AC. A new method for studying gut transit-times using radiopaque markers. Gut 1969;10:842.

${ }^{3}$ Fischler F. Zur Frage der verstopfenden Wirkung des Kakaos und über eine Verhütung dieser Wirkung. Munch Med Wochenschr 1933 $80: 534$.

${ }^{4}$ Czok G. Zur Frage der biologischen Wirksamkeit von Methylxanthinen in Kakaoprodukten. Z Ernaehrungswiss $1974 ; 13: 165$.

5 Fredholm BB, Hedqvist P, Vernet L. Effect of theophylline and other drugs on rabbit renal cyclic nucleotide phosphodiesterase, $5^{\prime}$-nucleotidase and adenosine deaminase. Biochem Pharmacol 1978;27:2845.

(Accepted 12 December 1980)

Departments of Gastroenterology and Clinical Chemistry, Hvidovre Hospital, University of Copenhagen, Denmark

LISELOTTE HØJGAARD, medical student

SUSANNE ARFFMANN, MD, registrar in medicine

MAJA JØRGENSEN, MD, registrar in clinical chemistry

EINAR KRAG, MD, chief physician in gastroenterology

\section{Pseudomembranous colitis after treatment with metronidazole}

Pseudomembranous colitis is a rare condition that may complicate the administration of certain antimicrobial agents. The most common of the many antibiotics that have been implicated are lincomycin and clindamycin. We report a case that followed a short course of intrarectal metronidazole used prophylactically in a patient undergoing emergency appendicectomy. To our knowledge there has been no recorded case of the condition in association with metronidazole alone. This has important implications as metronidazole has been suggested as a therapeutic agent to treat this condition.

\section{Case report}

A 13-year-old girl was admitted with a history of abdominal pain. Acute Apendicitis was diagnosed and appendicectomy was performed. Histological examination showed early focal appendicitis. She was given prophylactic metronidazole rectally $1 \mathrm{~g}$ before operation and $500 \mathrm{mg}$ three times daily for three days after operation. On the fifth day after operation she began to fee unwell, complaining of nausea and dizziness. She developed diarrhoea containing mucus and fresh blood. These symptoms persisted, and sigmoidoscopy two days later showed an inflamed rectal mucosa, biopsy specimens of which showed typical features of pseudomembranous colitis Histological examination showed disrupted crypts, distended by mucin and polymorphs. There was also focal destruction of crypts with loss of the epithelial surface (figure). A mushroom-shaped pseudomembrane consisting of epithelial debris, mucus, polymorphs, and fibrin was adherent to the underlying mucosa and there was an abrupt change to the normal mucosa at the edge of the lesion.

A minor degree of clinical improvement followed, and repeat sigmoidoscopy on the ninth day after operation showed a yellow membrane partly adherent to the underlying mucosa at $15 \mathrm{~cm}$. Repeat biopsy findings confirmed the previous findings. Specimens of faeces on days eight and 10 were culture-negative for campylobacter, shigella, salmonella, staphylococci, 